Econometric estimation of nested production functions and testing in a computable general equilibrium analysis of economy-wide rebound effects

Karen Turner

Ian Lange

Patrizio Lecca

Soo Jung Ha

Stirling Economics Discussion Paper 2012-08

May 2012

Online at

http://www.management.stir.ac.uk/research/economics/workingpapers 


\title{
Econometric estimation of nested production functions and testing in a computable general equilibrium analysis of economy-wide rebound effects
}

\author{
By Karen Turner $^{1}$, Ian Lange ${ }^{1}$, Patrizio Lecca ${ }^{2}$ and Soo Jung $\mathrm{Ha}^{3}$
}

1 Division of Economics, Stirling Management School, University of Stirling, UK

2 Fraser of Allander Institute, Department of Economics, University of Strathclyde, UK

3 Korean Research Institute for Human Settlements, South Korea

* Corresponding author: karen.turner@stir.ac.uk

\section{Acknowledgements:}

The research reported in this paper was supported by the UK Economic and Social Research Council under the First Grants Initiative (ESRC grant ref: RES-061-25-0010).

Keywords: general equilibrium, KLEM production function, separability assumptions.

JEL codes: C68, D57, D58, R15, Q41, Q43

\begin{abstract}
Quantitative models, such as computable general equilibrium (CGE), that are increasingly used to inform policy processes rely on a number of assumptions concerning how good and services are produced. Previous research has shown that the elasticity of substitution between inputs and the structure in which these inputs interact can have large impacts on model output. However, the choice of elasticities and production structure is often made without the support of statistical evidence. This research aims to address these points by estimating nesting structure and the elasticities of substitution therein across a number of sectors in the UK then testing the implications of introducing these estimates to parameterise a CGE model that is then used to simulation the economy-wide impacts of increased efficiency in the productive use of energy.
\end{abstract}




\section{Econometric estimation of nested production functions and testing in a computable general equilibrium analysis of economy-wide rebound effects}

\section{Introduction}

Multi-sectoral computable general equilibrium (CGE) models have become increasingly widely used to analyse the economy-wide impacts of a range of energy and environmental issue and policies (e.g. see Bergman, 2005, for a review). In particular, CGE models are the most commonly used framework to investigate economy-wide rebound effects from increased efficiency in the use of energy in production (see Dimitropoulos, 2007; UKERC, 2007). Research (e.g. Saunders, 2000, 2008; Turner, 2009; UKERC, 2007) has shown that the elasticity of substitution between energy and other inputs in production is a dominating factor governing both direct and economy-wide rebound effects when energy efficiency increases in production. Moreover, recent research by Lecca et al (2011) demonstrates that results of shocks involving changes in energy demand will be sensitive to how energy enters and combines with other inputs in the nested production functions commonly employed in CGE models; that is, to the 'separability' assumptions made in deciding how to introduce different inputs.

The appropriate means of introducing energy to production functions has been a source of debate more generally for a number of years (with Berndt and Wood , 1975, and Griffin and Gregory, 1976, providing early production function estimates, focussing particularly on capital-energy substitutability/complementary; see Lecca et al, 2011, for a review of the debate since). However, while CGE modellers often draw on econometric work to inform elasticities of substitution and/or subject results to parametric sensitivy analysis regarding the values associated with elasticities of substitution between inputs, it is rarely the case that the structure of the production function is statistically informed or subjected to testing. The limited number of examples of estimating nested production functions including energy include Kemfert (1998) and Van der Werf (2008), but these do not extend to testing in CGE models.

The research reported in this paper aims to address these points by estimating the appropriate nesting structure between capital, labour and energy inputs to production, and the values of elasticities of subsitution therein before testing in a CGE modelling framework. We follow Van der Werf's (2008) method of estimating a logged system of equations for different nested combinations of these three inputs. However, we extend by estimating for different sectors within the target economy of the UK. We then use the best fitting estimates of production function nestings and 
elasticities therein for the parameterisation of a 21-sector CGE model of the UK economy (we also estimate comparative results for the US, which are presented in an appendix), and go on to simulate the impacts of an increase in energy efficiency in all UK production sectors. Focussing on the economy-wide rebound effect as a key variable of interest, we consider the value-added gained from the econometric input to the model.

The reader should note that this is an early working paper, produced with the aim of eliciting comments and feedback on the econometric work in particular. A key limitation of the work reported here is that our estimates only cover three of the four commonly considered KLEM inputs. That is, we do not consider how non-energy Material inputs enter the nested production function, limiting our attention to cases where Energy enters the nested production function through the value-added nest (i.e. combining first with capital, K, or Labour). This is due to difficulties in estimating a hierarchical production function with more than two nests using the Van der Werf (2008) methodology. Moreover, we are concerned about the fit particularly of the upper/outer nest equations. There may also be alternative methods of estimating and specifying production functions for use in a CGE modelling framework. For example, Adkins et al (2003) consider the recommendation of Partridge and Rickman (1998), who cite and question the dominance of the nested CES approach in regional CGE models, and use a Bayesian framework to estimate Translog cost functions to consider own- and cross-price elasticities between different capital, labour and energy. While more flexible functional forms may be used instead of nested production functions in CGE models (e.g. Hertel and Mount, 1985; Despotakis and Fisher, 1988; Li and Rose, 1995), it is less tractable to do so where there are multiple inputs and/or multiple sectoral outputs (Naqvi, 1998). A possible solution may be that argued by Adkins et al (2003), who suggest a combination of the two approaches may be used, with the results of estimation of more flexible translog cost functions used to inform nested CES substitution parameters.

Moreover, our continued research activity in this area involves improving the specification of the CGE modelling framework more generally, particularly in terms of the treatment of energy supply and investment and price determination decisions therein. Therefore, we welcome comments and feedback on the work more generally.

\section{The issue of separability assumptions in production functions for CGE models}

The CGE modelling literature identifies the elasticity of substitution between inputs in the production function and the structure in which these inputs interact among these assumptions as a 
key issue, as does the wider energy economics literature. While, as noted above, some CGE modellers use flexible functional forms to retain as much flexibility as possible in terms of substitutability between inputs, it is more common for modellers to employ a nested CGE production function with pairwise substitutions at each nest (to increase the substitution possibilities between inputs where there are more than two). For example, producers may choose a composite of capital (K) and labour (L) inputs first, which then combines with energy (E) and other intermediates (generally referred to as materials, $M$, in the common KLEM specification) in a nested CES production function (with Cobb-Douglas and Leontief adopted at nests where substitutability between inputs is unitary or zero respectively). This case is illustrated in Figure 1.

\section{Figure 1: Example Of A CES Hierarchical/Nested Production Function}

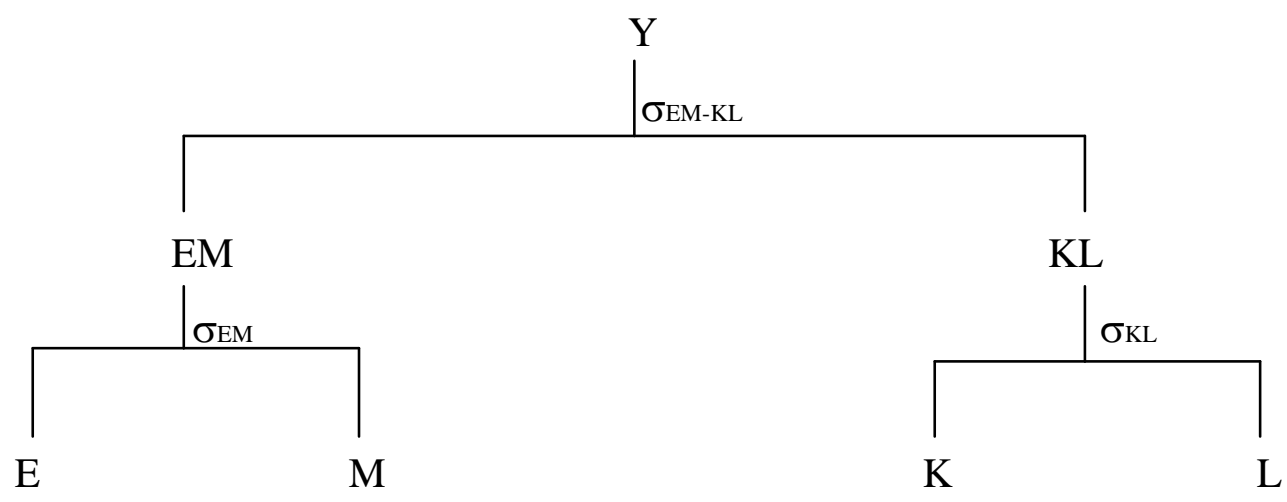

However, as we demonstrate in Lecca et al. (2011), the imposed structure of the production function and elasticity values therein may greatly impact on model results. A nested production structure requires the imposition of separability among the inputs. That is, while employing a nested production function allows differing substitutability overall where there are more than two inputs to production, such a structure only allows substitutions between pairs of inputs at any level in the hierarchy. Where one of the input nests involves a composite input resulting from substitution between another pair of inputs at a lower level (for example the capital-labour, or value-added composite in Figure 1) this has the implication that both of the inputs incorporated in the composite must substitute equally well for the third input (in Figure 1, energy and/or materials).

For this reason, in this paper we attempt to extend on the Lecca et al. (2011) analysis by econometrically estimating the appropriate structure and parameter values for nested production functions for different production activities/sectors for the case study of the UK (we provide a US comparison of our econometric work in an appendix). While CGE models do commonly identify a 
KLEM production function, where capital, labour, energy and other material/intermediate inputs are identified, in the first instance follow Van der Werf (2008) in attempting to estimate a simpler production function that focuses on the nesting and substitutability between just three inputs, capital, labour and energy. Thus, we estimate elasticities of substitution across three permutations of a 2-level constant elasticity of substitution (CES) production function (KL-E, KE-L and LE-K). These are estimated at country and sectoral level for the UK, with 27 production sectors identified.

\section{Econometric model}

\subsection{Existing literature}

Berndt and Wood (1975) were the first to estimate the elasticities of substitution with energy in a production function. Using US manufacturing data from 1947-1971, a logged four input (materials being the fourth) production function is estimated with 3 Stage Least Squares. Griffin and Gregory (1976) use manufacturing data across nine OECD countries for the years 1955, 1960, 1965, and 1969 to estimate a logged four input production function. These two early studies have many common results, but the main difference is whether energy and capital are substitutes or complements. Griffin and Gregory (1976) results imply they are substitutes while Berndt and Wood (1975) results imply they are complements. This reflects a wider debate in the energy economics literature, where questions are raised such as whether the substitutability (or not) between energy and capital varies over time, and/or whether this will differ between energy and different types of capital, for example different vintages, and/or separation between physical and human, financial capital etc.

Following this last point Markandya and Pedroso-Galinato (2007) use non-linear least squares to estimate how substitutable different types of capital (physical, human, land) are in National Income generation. They use a cross-sectional data across 2008 countries. The results suggest that elasticites between the measures of natural, physical and human capital are close to one, indicating a high degree of substitutability.

Van der Werf (2008) derives estimates of the elasticites of substitution for a three input, 2-level CES production function across the three permutations. Using panel data for 7 sectors across 12 countries over 19 years and the constraints imposed by cost minimization, a logged system of equations is estimated. Given the short time frame analysed, results are given by sector or country. His results generally suggest that the KL-E nesting provides the best fit. 
In this paper, we attempt to make a new contribution to the literature by first extending on the work of Van Der Werf by using a larger dataset for the UK to obtain UK-specific country- and sectorallevel estimates. We also compute corresponding results for the US. Moreover, in the case of the UK we also consider the use of the econometric estimates to inform a the calibration process of a CGE modelling approach, as an example of the wide range of quantitative models that are increasingly commonly being used to inform policy evaluation.

\subsection{Data and method}

Data for the econometric estimation for the UK are obtained from Dale Jorgensen's (2008) KLEM project for the EU. The data series are also publicly available from the EU KLEMS website (http://www.euklems.net). We aggregate $27 \mathrm{UK}$ production activities from 93 sectors over the years 1970-2005. Gross output, intermediate energy inputs, compensation of employees and real fixed capital stocks are extracted as the quantities data for each year and sector - see Table 1 . The price of gross output, gross fixed capital formation, labour, and energy are normalized to a 1995 base year.

For the US comparison (reported in Appendix 1) data are obtained from Jorgenson (2007). The US data is reported for 35 sectors over the years 1961-2005. Unfortunately, consistent sectoral aggregations could not be obtained across the UK and US but there is significant overlap in around 18 sectors to allow some comparison.

Table 1. Variables from EU KLEM dataset used in econometric estimation for the UK

\begin{tabular}{|c|l|}
\hline variables & 1995 British pounds, Index 1995=1, 1970-2005 \\
\hline$P_{K}$ & Gross fixed capital formation price index \\
\hline$P_{L}$ & Compensation of employees index \\
\hline$P_{\mathrm{Y}}$ & Gross output price index \\
\hline$P_{\mathrm{E}}$ & Intermediate energy inputs value index/Energy input volume index \\
\hline $\mathrm{K}$ & Real fixed capital stock \\
\hline $\mathrm{L}$ & Number of employees \\
\hline $\mathrm{Y}$ & Gross output \\
\hline $\mathrm{E}$ & Intermediate energy inputs \\
\hline
\end{tabular}

Estimating production functions empirically can be done either using non-linear least squares, or OLS if the data have been logged. Non-linear least squares estimation involves specifying the production function and iterating the parameters until the sum of squared residuals are minimized. 
Here, in the case of a three input CES production function, there are seven parameters to estimate. However, when we attempted this estimation method the estimated elasticities did not make economic sense for many of the industries.

Therefore, the next estimation method we attempted, and report here, is a logged OLS estimation. The methodology of van der Werf (2008) is employed to estimate all three nests of a 2-level CES production functions with capital, labour, and energy by sector for the UK first at country level, then at sectoral level within. We carried out country level estimations for of all three nests using the entire sample and then for 1990-2005 for comparative purposes (see Table 2). The estimation equations, taking the case of the KL-E nesting are

$$
\begin{aligned}
& \% \Delta(E-Y)=\alpha+\sigma_{K L, E}\left(P_{Y}-P_{E}\right)+\varepsilon \\
& \% \Delta(\text { CostShareK })=\gamma+\left[\left(\sigma_{K, L}-1\right)\left(\Delta \ln \left(V_{K}+V_{L}\right)-P_{Y}-Y\right)\right]+\left[\left(1-\sigma_{K, L}\right)\left(P_{K}-P_{Y}\right)+\eta\right. \\
& \% \Delta(\text { CostShareL })=\delta+\left[\left(\sigma_{K, L}-1\right)\left(\Delta \ln \left(V_{K}+V_{L}\right)-P_{Y}-Y\right)\right]+\left[1-\sigma_{K, L}\right)\left(P_{L}-P_{Y}\right)+v
\end{aligned}
$$

The estimation equations are derived from an assumption of cost minimization with the choice of the three inputs and price-taking behaviour in the industry. The first equation explains the percentage change in the ratio of energy and output from the growth rate of their relative price $\mathrm{p}_{\mathrm{Q}^{-}}$ $\mathrm{p}_{\mathrm{E}}$, with the coefficient being the outer/upper nest elasticity $\left(\sigma_{K L, E}\right)$. The left side of other two equations are the percentage change of the cost-share of input $\mathrm{K}$ or $\mathrm{L}$ in the costs of producing a composite (KL). Restrictions are added in estimation to ensure that the coefficients in the second and third equations are equal. Although, similar to Van der Werf (2008)'s result, we find that the restrictions are rejected, we proceed with the restrictions to find parameters of the nested CES production function that fit the data best in the sense of comparing the empirical relevance of the 3 different nesting structures for CGE modelling applications.

\section{Econometric results}

The results in Table 2 show that for all three alternative nestings, we get elasticity estimates that are statistically significant with the full 35 year data set (1970-2005). There is less significance, particularly on the lower nest when the dataset is restricted to 1990-2005. Goodness of fit, which we measure by $\mathrm{R}^{2}$ on each of the equations involved in the estimation is relatively high on the $\mathrm{y}_{2}$ and $\mathrm{y}_{3}$ equations used to estimate the lower nest in all three cases, but relatively low on the $\mathrm{y}_{1}$ equation used to estimate the outer/upper nest in all three. 
Table 2. Elasticities estimated for aggregate UK production

\begin{tabular}{|l|ll|ll|ll|}
\hline & Sigma KL,E & Sigma KL & Sigma KE,L & Sigma KE & Sigma LE,K & Sigma LE \\
\hline UK (70-05) & $\mathbf{0 . 1 3} * * *$ & $\mathbf{0 . 0 4} * * *$ & $\mathbf{- 0 . 0 8 * * *}$ & $\mathbf{- 0 . 1 5 * * *}$ & $\mathbf{0 . 3 1} * * *$ & $\mathbf{0 . 1 8 * * *}$ \\
& & R-sq y2 0.82 & & R-sq y2 0.79 & R-sq y2 0.93 \\
& R-sq y1 0.023 & R-sq y3 0.92 & R-sq y1 0.015 & R-sq y3 0.74 & R-sq y1 0.11 & R-sq y3 0.70 \\
\hline UK (90-05) & $\mathbf{0 . 0 6}$ & $\mathbf{0 . 1 2} * * *$ & $\mathbf{0 . 0 2}$ & $\mathbf{0 . 3 4 * * *}$ & $\mathbf{0 . 1 4} * * *$ & $\mathbf{0 . 1 6 * * *}$ \\
& & R-sq y2 0.48 & & R-sq y2 0.64 & R-sq y2 0.92 \\
& R-sq y1 0.00 & R-sq y3 0.93 & R-sq y1 0.00 & R-sq y3 0.59 & R-sq y1 0.08 & R-sq y3 0.21 \\
\hline
\end{tabular}

Overall, the LE-K specification would seem to perform best, followed most closely by the first, KLE, but without a basis for a clear decision. However, none of the specifications perform well in terms of the outer/upper level estimate.

This raises the question of how we interpret the results. If we take the KL-E nesting first, Table 2 suggests that labour and capital substitute with an elasticity of 0.04 , then this composite combines with energy with an elasticity of 0.13 . This implies that both labour and capital both substitute equally well for energy with the elasticity of 0.13 .

However, on the KE-L specification, there is a negative value for the elasticity of substitution between $\mathrm{K}$ and $\mathrm{E}$. At -0.15 , this implies that if there is a unit change in the relative price of capital (or energy) there is a reduction in the use of energy (or capital) of 15\%. Thus, they can be interpreted as complements (and a value of 0, represented by Leontief technology) would be applied by a CGE modeller. This is not consistent with the positive elasticity (0.13) implied under the first specification.

On the other hand, in the third specification, LE-K, the estimated elasticity of substitution between $\mathrm{L}$ and $\mathrm{E}, 0.18$, is much more consistent with what is implied by the first specification. However, the upper level elasticity estimate between LE and K suggests that both energy and labour substitute equally well for capital at 0.31 , which is inconsistent with the K-E elasticity of -0.15 from the second specification and the L-K one of 0.04 in the first.

Therefore, the three specifications are telling us quite different things, suggesting that the separability assumptions embodied in the nesting chosen for the production function are indeed very important. As noted above, the overall $\mathrm{R}^{2}$ statistics implied that the third, LE-K, specification is the best fit of the three, followed most closely by the first, KL-E. However, none perform well in terms of the upper level estimate. 
Moreover, it may be difficult to find a specification/nesting that may be applied across all production sectors in the UK. For this reason we also carried out sectoral level estimates, which are discussed below. However, prior to discussing these it is worth noting that country level estimates using US data for the full 44 years these are available seemed to give us a clearer story. At the country-level for the US, estimated elasticities for all three alternative nestings were also statistically significant at least at the 5\% level (at least) over the longer time period. Moreover, in the KL-E and LE-K cases we found the same elasticities at both nests, with values of 0.11 in the KL-E case and 0.13 in the LE-K case. This suggests that in each case the nesting/separability assumption employed does not matter and the small difference between 0.11 and 0.13 would be unlikely to have a great deal of impact on results from a CGE model. This implies that, in the case of the US, a single level CES function could be employed for the three inputs, with an elasticity of set between 0.11 and 0.13 (though results we found for the third nesting, KE-L, do not support this, though the odd results with the KE-L specification in general, across both the UK and US, may suggest problems with how capital is reported in the data used).

However, when we re-ran the US estimates for a shorter time period (1990-2005), we found that the estimated elasticities tend to be larger and more statistically significant, and with variation in the elasticity values at the upper and lower nests in the KE-L case in particular. The fact that the estimates became larger also implies that there may be some problem with the data across the full time period (over shorter time periods we would generally expect to observe lower elasticities). However, the main point is that the variation in results across specifications and at the upper and lower levels means the same problem as described above for the UK: the different nestings are telling us different things about the substitutability between the three different inputs, with the implication that nesting/separability assumptions adopted does matter and some choice needs to be made between the different nestings.

Moreover, the sector-level results for the US that are reported in the Appendix to this paper for the full 64 year sample show more variation, suggesting that application of the country-level estimates of both parameter values and nesting structure may be misleading if applied in a multi-sector CGE modelling framework. Appendix 1 shows the sectoral level results obtained using the US data over the years 1961-2005. There is significant variation in the estimates of the elasticity of substitution between sectors and within sectors by input structure. Overall, 65\% of all coefficients are statistically different than zero at the $10 \%$ level or smaller. The KE-L permutation shows the least amount of coefficients statistically significantly different from zero at the $10 \%$ level or smaller. The other two permutations have the same number of coefficients statistically different from zero. 
Only 6 (out of 210) of the estimates are negative and statistically different than zero, with the "Petroleum and Coal Products" sector contributing half of them. A negative elasticity implies that the two inputs are complements rather than substitutes. Only 2 estimates, the inner [KL]E nest of the "Oil \& Gas Extraction" and the inner [LE]K nest of the "Transportation Equipment" sector, are statistically larger than 1. Four sectors' ("Agriculture", "Non-metallic Mining", "Furniture \& Fixtures", and "Fabricated Metal") estimates are statistically equivalent for both the upper and lower nests for all three permutations.

However, here, given the availability of a CGE modelling framework to test the implications of applying the econometric results in the parameterisation process, we focus our attention on the UK sectoral results, which are reported in Table 3 (below, where we have highlighted the sectors for which we seem to get relatively good estimates and which can be easily mapped to the CGE model sectors introduced in Section 4).

The UK production function results are more variable than the US results. Overall, $75 \%$ of all coefficients are statistically different than zero at the $10 \%$ level or smaller. No permutation stands out as having few coefficients which are not statistically different than zero. Over half of the KE-L permutation coefficients are negative and statistically different than zero. A small number of coefficients in the other two permutations are negative and statistically different than zero. The inner LE-K nest for the "Electrical and Optical Equipment" and "Transport and Storage" sectors are statistically larger than 1 . No sector estimates are statistically equivalent across the three permutations for the UK. This is partially driven by the fact that most of the KE-L coefficients are negative (again, problems with this specification imply that something may be wrong with how we report capital in the data). The "Agriculture, Hunting, Forestry and Fishing" sector has negative and statistically significant estimates for both nests in the KE-L and LE-K permutations. All but one of the six estimates for the "Mining and Quarrying" sector are statistically equal to zero. All upper nests of the "Coke, Refined Petroleum and Nuclear Fuel" sector are statistically equal to zero, implying only the lower nest matters.

Generally, the difficulties encountered in interpreting the econometric results reported here, and also issues in terms of large differences between sectoral level estimates for the UK and US in activities that may be expected to be similar across countries - e.g. "Chemicals"/"Chemicals and Chemical"- raise questions in terms of the reliability of our work here. This may be in terms of how we have used the KLEM data and/or the estimation methods. 
Table 3. Elasticities estimated for different UK production activities/sectors

\begin{tabular}{|c|c|c|c|c|c|c|}
\hline & $\begin{array}{l}\text { Sigma } \\
\text { KL,E }\end{array}$ & Sigma KL & $\begin{array}{l}\text { Sigma } \\
\text { KE,L }\end{array}$ & Sigma KE & $\begin{array}{l}\text { Sigma } \\
\text { LE,K }\end{array}$ & Sigma LE \\
\hline Agriculture, hunting, forestry and fishing & 0.17 & $-0.1^{*}$ & $-0.74 * * *$ & $-0.36 * * *$ & $-0.73 * * *$ & $-0.35 * * *$ \\
\hline Mining and quarrying & -0.23 & 0.08 & 0.42 & $0.44 * * *$ & 0.02 & 0.08 \\
\hline Food, beverages and tobacco & 0.2 & -0.01 & $-0.64 * * *$ & $-0.49 * * *$ & $0.54 *$ & $0.36 * * *$ \\
\hline Textiles, textile, leather and footwear & $0.34 * *$ & $0.19 * * *$ & $0.44 * * *$ & $0.36 * * *$ & $0.83 * * *$ & $0.82 * * *$ \\
\hline Wood and of wood and cork & 0.16 & -0.03 & $-0.45^{* *}$ & $-0.49 * * *$ & $0.64 * * *$ & $0.58 * * *$ \\
\hline Pulp, paper, printing and publishing & $0.28 * *$ & $0.08 * * *$ & $-0.63 * * *$ & -0.05 & $0.62 * * *$ & $0.52 * * *$ \\
\hline Coke, refined petroleum and nuclear fuel & 0.68 & $0.79 * * *$ & 0.19 & $0.31 * * *$ & 0.19 & $0.28 * * *$ \\
\hline Chemicals and chemical & 0.11 & -0.05 & $-0.56 * * *$ & $-0.24 * * *$ & $0.84 * *$ & $0.8 * * *$ \\
\hline Rubber and plastics & $0.34 * *$ & $0.12 * * *$ & $-0.28 * * *$ & $-0.36 * * *$ & $0.83 * * *$ & $0.79 * * *$ \\
\hline Other non-metallic mineral & $0.21 * *$ & 0.07 & 0.27 & $0.18 * * *$ & $0.94 * * *$ & $0.94 * * *$ \\
\hline Basic metals and fabricated metal & $0.29 * *$ & $0.18^{* * *}$ & 0.06 & -0.01 & $0.58 * *$ & $0.5 * * *$ \\
\hline machinery, NEC & $0.2^{* *}$ & $0.15^{* * *}$ & $0.74 * *$ & $0.73 * * *$ & $0.52 * * *$ & $0.45^{* * *}$ \\
\hline Electrical and optical equipment & 0.27 & 0.06 & $-0.43 * * *$ & $-0.25 * * *$ & $1.18 * * *$ & $1.18 * * *$ \\
\hline Transport equipment & $0.27 * *$ & $0.14 * * *$ & 0.04 & -0.07 & $0.77 * * *$ & $0.75^{* * *}$ \\
\hline Manufacturing Nec, Recycling & $0.19 *$ & $0.1^{* *}$ & $-0.37 * *$ & -0.14 & $0.57 * * *$ & $0.5^{* * *}$ \\
\hline Electricity, gas and water supply & 0.29 & $0.16^{* *}$ & $-0.5^{* *}$ & $-0.37 * * *$ & -0.09 & $-0.22 * * *$ \\
\hline Construction & -0.01 & $-0.13 * * *$ & $-0.16^{*}$ & $-0.38 * * *$ & $0.51 * * *$ & $0.37 * * *$ \\
\hline Wholesale and retail trade & 0.25 & $0.08 * * *$ & $-0.17 * * *$ & $-0.25 * * *$ & $0.37 * * *$ & $0.19 * * *$ \\
\hline Hotels and restaurants & $0.15^{*}$ & 0.01 & $-0.14 * *$ & $-0.32 * * *$ & $0.35^{* *}$ & $0.2 * * *$ \\
\hline Transport and storage & 0.2 & 0.01 & $-0.3 * * *$ & $-0.35^{* * *}$ & $1.07 * * *$ & $1.08 * * *$ \\
\hline Post and telecommunications & -0.06 & $-0.13 * * *$ & $-0.11 * *$ & -0.17 & $0.63 * *$ & $0.48 * * *$ \\
\hline Financial intermediation & -0.01 & -0.03 & $-0.22 * * *$ & $-0.25^{* * *}$ & $0.24 * *$ & $0.1 * * *$ \\
\hline Real estate, renting and business activities & 0.04 & 0 & $-0.11 * *$ & $-0.25 * * *$ & $0.31 * *$ & $0.16^{* * *}$ \\
\hline Public admin and defence, social security & $0.16^{*}$ & 0.01 & -0.36 & $-0.29 * * *$ & $0.38 * * *$ & $0.23 * * *$ \\
\hline Education & 0.07 & -0.02 & $-0.46^{* *}$ & $-0.53 * * *$ & $0.23 *$ & $0.11 * * *$ \\
\hline Health and social work & 0.03 & 0 & -0.06 & $-0.31 * * *$ & $0.34 * *$ & $0.2 * * *$ \\
\hline Other community, social and personal services & 0.03 & -0.03 & $-0.12 *$ & $-0.26 * * *$ & $0.56^{* * *}$ & $0.43 * * *$ \\
\hline
\end{tabular}

$*, * *, * * *$ indicates $10 \%, 5 \%$, and $1 \%$ significance, respectively, against a null of sigma $=0$

\section{Computable general equilibrium model - UKENVI}

In this paper we develop the UKENVI CGE modelling frameworks of the UK economy that has been employed in our previous research (Allan et al., 2007; Turner, 2009). UKENVI is the energyeconomy-environment version of the basic AMOS CGE framework developed by Harrigan et al 
(1991). ${ }^{1}$ The UKENVI model employed here is calibrated on a 2004 social accounting matrix for the UK, the main component of which is an analytical (symmetric, producer price) input-output table constructed by the Fraser of Allander Institute at the University of Strathclyde. This may be accessed at http://www.strath.ac.uk/fraser/research/2004ukindustry-byindustryanalyticalinputoutputtables/. A condensed descriptions/equation listing of the UKENVI model can be found in Turner (2009). Here, we focus on the novel elements of model specification applied in this paper.

We develop the UK model to allow a more flexible treatment of energy as an input to production, allowing simulation with alternative nested KLEM production functions. These are shown in Cases $\mathrm{A}, \mathrm{B}$ and $\mathrm{C}$ in Figure 2 (below). Note that it is possible to specify further alternative production functions including the KE-L case we have econometric results for. Note that Figure 2 simplifies with respect to the Energy input - this is actually a (here single level) composite of four energy types - coal, gas, refined oil production and electricity - which are each in turn a composite of domestic and imported commodities.

In this respect, one crucial point to note here is that in any of the KLEM production functions we specify in UKENVI Energy is treated as a produced input. That is, energy is the output of the four UK energy production sectors - Coal, Refined Oil, Gas and Electricity - and the corresponding rest of the world (ROW) sectors from which UK producers and final consumers import. This is an important point as it means that changes in local energy supply prices resulting from variations in capacity and transport costs can be identified (Anson and Turner, 2009). It may also explain why some modellers would select the type of KLEM production structure shown in Figure 1 above, where Energy enters the intermediate rather than primary input block of the nested production function. An example is Beauséjour et al (1995), who distinguish energy from natural resources, which are treated as primary inputs alongside value-added (labour and capital).

Households, Firms and Government are the three domestic institutional sectors. Households' and firms' behaviour are the result of an optimization process with myopic expectations; Government real consumption is held constant in the current application (though this can be endogenised). There is one external (ROW) institution. Since the UK is too small for any price effects in international market to feed back to the target economy, we adopt assumptions typically used for a small open economy in that ROW prices are taken to be exogenous.

\footnotetext{
${ }^{1}$ AMOS is an acronym for A micro-macro Model Of Scotland, deriving its name from the fact the framework was initially calibrated on Scottish data.
} 
Figure 2: Alternative CES Hierarchical/Nested Production Functions in UKENVI

A. Case 1 default

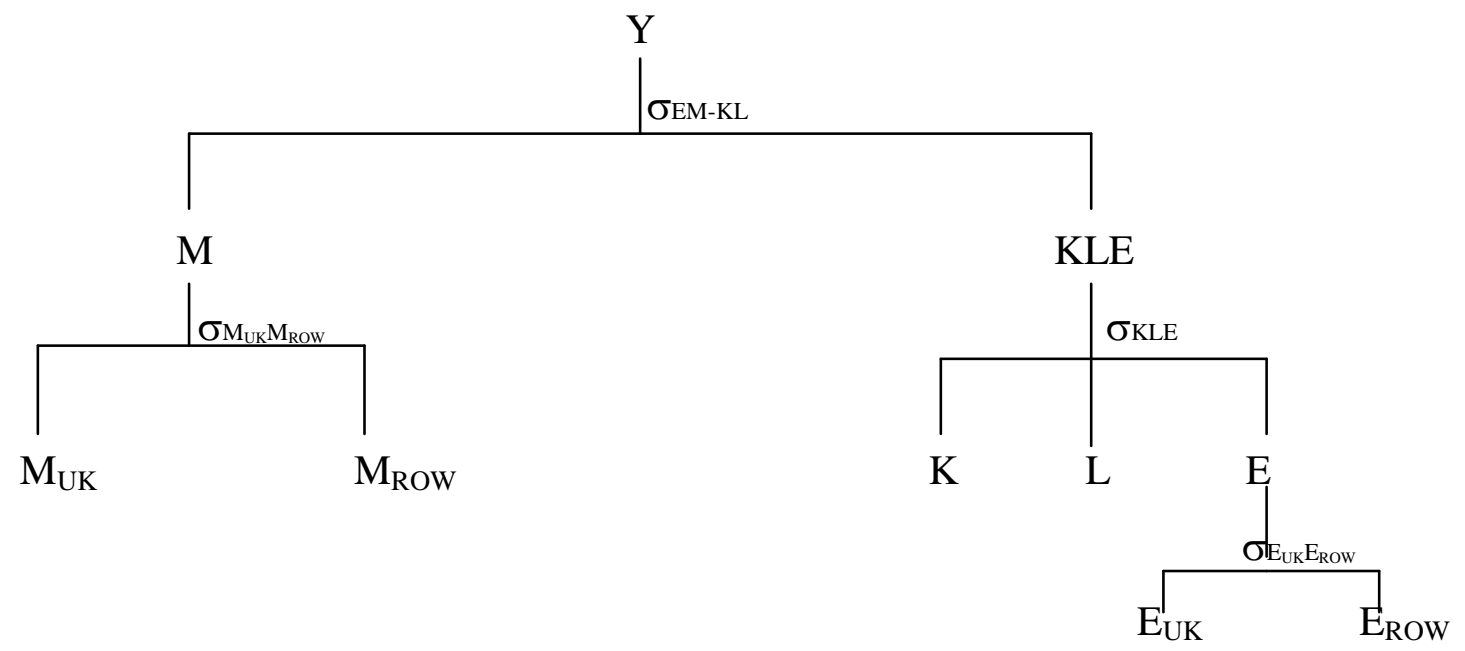

B. Case 2 KLE nesting

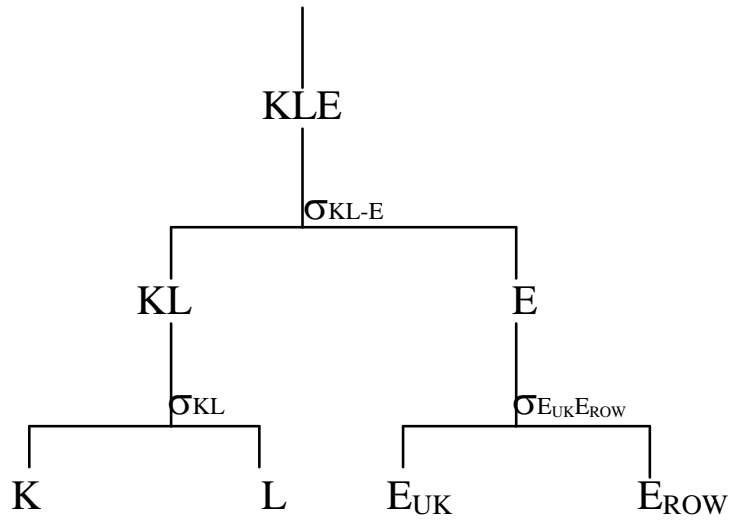

C. Case 3 KLE nesting

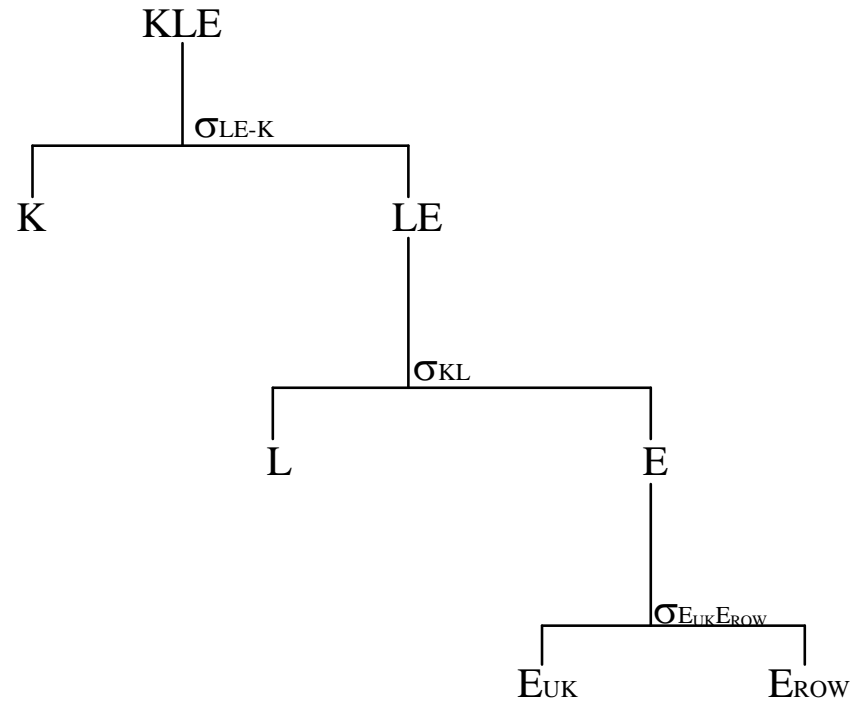


Intermediate, capital and consumption goods produced locally and imported are considered as imperfect substitutes. UK domestic goods combine with imported goods under the so called Armington assumption (Armington, 1969) through a CES function (see below).

The outputs of UK production sectors are purchased by industries and by domestic and external final consumers. Each industry in the region produces commodities that can be exported or sold in the regional market. An export demand function closes the model where external demand is sensitive to changes in relative prices between domestic and external prices.

The capital stock is fixed in the short-run, which (given the time period covered by the SAM) we take to be the first year after a disturbance is introduced. Thereafter, adjustment is made to long-run equilibrium, where the capital stock is fully adjusted. Within each period, both the total capital stock and its sectoral composition are fixed. Each sector's capital stock is then updated between periods via a simple capital stock adjustment procedure, according to which investment equals depreciation plus some fraction of the gap between the desired and actual capital stock. The desired capital stock is determined on cost-minimisation criteria. The actual stock reflects last period's stock, adjusted for depreciation and gross investment. The economy is assumed initially to be in long-run equilibrium, where desired and actual capital stocks are equal.

This treatment is wholly consistent with sector investment being determined by the relationship between the capital rental rate and the user cost of capital. The capital rental rate, or return on capital, is the rental that would have to be paid in a competitive market for the (sector specific) physical capital while the user cost is the total cost to the firm of employing a unit of capital. Given that we take the interest, capital depreciation and tax rates to be exogenous, the capital price index is the only endogenous component of the user cost. If the rental rate exceeds the user cost, desired capital stock is greater than the actual capital stock and there is therefore an incentive to increase capital stock (and vice versa in the case of the 'disinvestment effect' defined in Turner, 2009). The resultant capital accumulation puts downward pressure on rental rates and so tends to restore equilibrium. In the long run, the capital rental rate equals the user cost in each sector, and the riskadjusted rate of return is equalised between sectors. We assume that interest rates are fixed in international capital markets, so that the user cost of capital varies with the price of capital goods.

In most of the simulations, the total labour stock (but not its sectoral composition) is assumed to be fixed with no natural population change or migration. However, in one scenario ( $3 b$ in Table 4) we allow the labour supply through migration from the rest of the world using a migration function of 
the Harris and Todaro (1970) type where in any period the decisions of migrants are positively related to the gap between UK and ROW real wages regional and negatively related to the gap between internal and external unemployment rates. In all cases we assume that wages are determined via a bargained real wage function in which the real consumption wage is directly related to workers' bargaining power, and therefore inversely to the unemployment rate (Blanchflower and Oswald, 1994).

Thus, UKENVI is an inter-temporal dynamic multi-sectoral general equilibrium model of the UK economy. In all but tone case we assume a fixed labour supply at the national level (but subject this to sensitivity analysis in case $3 \mathrm{~b}$ as explained above), with the dynamics coming through forward looking investment and consumption decisions by firms and households respectively. We simulate tracking the adjustment process of the economy over time, but focus initially on results for the conceptual time periods of the short-run (when capital stocks are fixed) and long-run (when the economy settles on a new post-shock steady state equilibrium). The econometric estimates are for long-run elasticities. However, assuming that investment decisions are required to introduce energy efficiency improvements, it would seem appropriate to use these from the outset in this forwardlooking model (unless there is reason to believe that some inertia exists in the short-term). We conduct simulations of a 5\% (exogenously determined) improvement in energy-augmenting technological progress that takes place in all 21 production sectors of the UK economy. The simulation is designed in this relatively simple way in order to focus on the determinants of the resulting economy-wide rebound effect, and to examine how this varies as we introduce the results of the nested production function estimations.

\section{CGE simulation results}

Economy-wide rebound effects from increased energy efficiency in production are determined through a series of related effects. First, as efficiency increases in the use of energy, the price of using energy relative to other inputs falls, inducing a positive substitution effect in favour of energy. Second, the improvement in productivity in production means that the price of output falls in all sectors directly targetted (all sectors here), but also in sectors using the output of targetted sectors as an input to production. Thus, there is a positive competitiveness effect, boosting economic activity throughout the economy, and associated energy use. Third, as incomes increase throughout the economy, there will be further positive impacts on production and consumption activity levels, including energy use. However, underlying all of these effects is the strength of the initial substitution effect and its impact on the cost of production in targetted sectors. 
Table 4. Impacts of introducing different nested elasticity estimates in simulating $5 \%$ increase in energy efficiency in UK production

\begin{tabular}{|c|c|c|c|c|c|c|c|c|c|c|c|c|}
\hline & \multirow{3}{*}{\multicolumn{4}{|c|}{ Central case comparis on }} & \multicolumn{8}{|c|}{ Estimated elasticities (with trade elasticities as $1 \mathrm{~b}$ and KLE-M pf elasticity 0.3 ) } \\
\hline & & & & & \multirow{2}{*}{\multicolumn{2}{|c|}{ Alternative 1: KL-E }} & \multicolumn{6}{|c|}{ Alternative 2: LE-K (best performance for UK and sectors) } \\
\hline & & & & & & & \multicolumn{4}{|c|}{ UK aggregate estimates, L mkt sensitivity } & \multirow{2}{*}{\multicolumn{2}{|c|}{$\begin{array}{l}\text { UK sectoral estimates } \\
\text { 3c. LE-K pf: sectoral } \\
\text { estimates } 8 \text { of } 21 \\
\text { sectors (see Table 2) }\end{array}$}} \\
\hline & \multicolumn{2}{|c|}{$\begin{array}{c}\text { 1a. Uniform pf } \\
\text { elasticities }(0.3), \text { trade } \\
\text { elasticities } 2.0 \\
\text { (AMOS default) }\end{array}$} & \multicolumn{2}{|c|}{\begin{tabular}{|c|} 
1b. Uniform pf \\
elasticities $(0.3)$, \\
export el 0.5 , import el \\
1.1
\end{tabular}} & \multicolumn{2}{|c|}{$\begin{array}{c}\text { 2. KL-E pf: K-L 0.04; } \\
\text { KL-E } 0.13\end{array}$} & \multicolumn{2}{|c|}{$\begin{array}{l}\text { 3a. LE-K pf: L-E } \\
0.18 ; \text { LE-K } 0.31 \\
\text { fixed L supply }\end{array}$} & \multicolumn{2}{|c|}{$\begin{array}{l}\text { 3b. LE-K pf: L-E } \\
0.18 ; \text { LE-K 0.31 } \\
\text { flexible L supply } \\
\text { (migration) }\end{array}$} & & \\
\hline & $\mathrm{SR}$ & LR & SR & LR & SR & LR & SR & LR & SR & LR & SR & LR \\
\hline GDP & 0.13 & 0.18 & 0.11 & 0.08 & 0.05 & 0.05 & 0.10 & 0.06 & 0.09 & 0.11 & 0.13 & 0.08 \\
\hline CPI & -0.16 & -0.16 & -0.25 & -0.22 & -0.22 & -0.21 & -0.25 & -0.20 & -0.28 & -0.27 & -0.27 & -0.23 \\
\hline Employment & 0.11 & 0.16 & 0.08 & 0.07 & 0.04 & 0.09 & 0.11 & 0.10 & 0.10 & 0.16 & 0.08 & 0.07 \\
\hline Unemployment rate & -1.01 & -1.42 & -0.71 & -0.67 & -0.36 & -0.85 & -1.03 & -0.87 & -0.93 & 0.00 & -0.71 & -0.59 \\
\hline Imports & 0.13 & 0.02 & -0.11 & -0.09 & -0.06 & -0.08 & -0.15 & -0.10 & -0.18 & -0.11 & -0.15 & -0.11 \\
\hline Energy output & -1.10 & -1.72 & -1.23 & -1.90 & -1.41 & -2.54 & -1.61 & -2.28 & -1.63 & -2.26 & -1.06 & -1.75 \\
\hline Non Energy output & 0.15 & 0.23 & 0.10 & 0.11 & 0.05 & 0.10 & 0.10 & 0.10 & 0.09 & 0.14 & 0.12 & 0.11 \\
\hline Domestic energy consumption & -1.33 & -2.02 & -1.42 & -2.18 & -1.64 & -2.91 & -1.85 & -2.61 & -1.88 & -2.59 & -1.22 & -2.01 \\
\hline Total energy demand by industries & -3.26 & -3.73 & -3.34 & -3.88 & -4.14 & -4.97 & -4.10 & -4.53 & -4.11 & -4.50 & -2.87 & -3.48 \\
\hline Reg. Energy demand by industries & -3.05 & -3.63 & -3.19 & -3.81 & -3.88 & -4.91 & -3.92 & -4.47 & -3.94 & -4.43 & -2.89 & -3.56 \\
\hline RUK. Energy demand by industries & -4.83 & -4.45 & -4.57 & -4.40 & -6.07 & -5.44 & -5.42 & -5.04 & -5.46 & -5.05 & -2.58 & -2.76 \\
\hline ROW. Energy demand by industries & -4.25 & -3.98 & -4.05 & -3.94 & -5.65 & -5.00 & -4.96 & -4.64 & -5.00 & -4.65 & -2.55 & -2.71 \\
\hline Household Energy Consumpiton & 2.03 & 1.21 & 2.01 & 1.09 & 2.70 & 1.11 & 2.20 & 1.11 & 2.14 & 1.09 & 1.99 & 1.07 \\
\hline Economy-wide rebound & 56.29 & 38.25 & 54.41 & 33.97 & 45.91 & 12.44 & 41.38 & 21.14 & 40.41 & 21.51 & 63.74 & 41.74 \\
\hline Economy-wide_Coal & -9.84 & -16.75 & -13.04 & -20.77 & -17.51 & -43.61 & -26.39 & -31.59 & -27.29 & -31.38 & -14.36 & -21.40 \\
\hline Economy-wide_Refined oil & 47.39 & 43.09 & 45.12 & 38.77 & 20.76 & 18.18 & 28.80 & 24.94 & 27.59 & 25.21 & 79.61 & 66.96 \\
\hline Economy-wide_Gas & 74.84 & 47.68 & 73.06 & 42.84 & 71.82 & 21.25 & 62.07 & 30.25 & 60.93 & 30.60 & 75.67 & 45.13 \\
\hline Economy-wide_Electricity & 59.51 & 36.74 & 57.87 & 32.64 & 54.66 & 10.74 & 45.86 & 20.09 & 45.05 & 20.53 & 57.57 & 32.58 \\
\hline
\end{tabular}


The various effects outlined above all involve direct and derived changes in energy demand which relate the economy-wide rebound effect to the general equilibrium price elasticity of demand for energy as opposed to simply the partial equilibrium price elasticities that determine direct rebound effects in response to the effective or implicit energy price change that triggers the rebound process. However, as explained in Turner (2009), the economy-wide response will also be impacted by supply-side factors, including any short and/or long run constraints on the availability of primary inputs to production (labour, capital and, where relevant, natural resources such as land), but also the response of energy producers/suppliers to changing demands for their outputs and any resulting impact on market prices. Thus Turner (2009) identifies two further effects, which put downward pressure on energy demand at the macro level and, thus, on economy-wide rebound effects.

The first of these is a negative multiplier effects resulting from reduced intermediate demand for energy inputs from energy supply sectors as demand for their output falls in response to the initial energy saving/pure efficiency effect when efficiency in energy use improves. Turner (2009) finds that, given that energy supply is often a relatively highly energy-intensive activity, the negative multiplier effects may be strong enough to entirely offset increased energy demand at the macrolevel resulting in net negative economy-wide rebound effects (and we find such a result in the case of coal in the simulation results reported in Table 4).

The second effect defined by Turner (2009), but initially identified by Allan et al. (2007) is a disinvestment effect. This arises where the initial contraction in demand for the output of energy suppliers causes a drop in the market price they face. Turner (2009 explains that such a drop in the actual as well the implicit price of energy will provide further impetus for economy-wide rebound effects. However, where the demand response is not sufficiently strong to prevent a decrease in the revenues of energy supplier sectors, there will be a negative impact on profitability and the return on capital, which may lead to shedding and/or non-replacement of capital stock. Such a tightening of energy supply conditions will require an offsetting increase in price in order to restore equilibrium in capital markets (see Section 4 above), which will in turn act to constrain energy demand and economy-wide rebound over the long run.

All of the general equilibrium effects outlined above are present in the simulation results presented in Table 4. Let us begin by considering the first 'central case comparison' in the first two numerical columns of Table 4, labelled case 1a. Here we have set up the model with the default specification imposed in previous UK analyses by Allan et al. (2007) and Turner (2009). The general specification is as outlined in Section 4. However, in terms of parameterisation, key elements of the 
model configuration are that fairly elastic values of 2.0 are applied to all import and export elasticities. In terms of the elasticities of subsitution between each of the aggregate KLEM inputs (and different energy types within $\mathrm{E}$ - due to the presence of multiple zeros in the non-energy intermediates matrix we assume Leontief technology in combining the 17 materials inputs in the $\mathrm{M}$ composite) these are assumed to take the value of 0.3 prior to the introduction of the econometric estimates from Tables 2 and 3. This means that the KLEM nesting in Figure 2 effectively collapses to a single level multiple input CES function.

With this default setting imposed we replicate the type of result found in the base case scenarios considered by Allan et al. (2007) and Turner (2009). That is, with the introduction of a 5\% increase in energy-augmenting technological progress in all 21 production sectors identified in the UK economy, production costs and output prices fall stimulating a process of productivity-led growth with a reduction in the CPI (-0.16\% over the long-run), and growth in GDP $(0.18 \%)$ as well as aggregate consumption, investment and employment. The increase in activity is greater over time as the capital stock adjusts through investment. The labour supply is fixed at the national level but the presence of a pool of unemployed labour allows expansion though with increased real wage demands partially off-setting the positive competitivenss effects of the efficiency improvement. The range of energy output and demand results in the lower part of the first two columns of Table 4 demonstrate that there is a net reduction in macro level energy use (2.02\%), with economy-wide rebound of less than $100 \%$ (38.25\%). However, note that the strength of the economy-wide rebound differs across the four different energy types identified, depending on the precise nature of their use (i.e. whether dominated by intermediate, local or external final consumption demands). In the case of coal, we observe a net negative economy-wide rebound effect (-16.75\% over the long-run), which is driven by the reduction in the intermediate input requirements of the electricity sector as it contracts. While not reported in the table, we observe reductions in the return on capital, investment demand and capital stocks in all four UK energy sectors and this disinvestment effect is reflected in the fact that economy-wide rebound is smaller over the long-run in all types of energy use.

In the second central case comparison, labelled case $1 \mathrm{~b}$, we adjust the default setting to reflect more recent analyses (e.g. Barrell et al., 2006) that suggest the trade elasticities imposed in our default UKENVI configuration may be too high for the contemporary UK economy. In particular, Barrell et al.'s (2006) analysis suggests that inelastic values $(<1)$ should be attached to export elasticities. Therefore, in $1 \mathrm{~b}$, which is highlighted in Table 4 to indicate that we take it as our main central case scenario here, we reduce export price elasticities for the outputs of all 21 sectors to 0.5 . We also reduce import elasticities but retain elastic values of 1.1 for all production sectors and consumers. In 
reading the results in the third and fourth numerical columns of Table 4, note that while there is no qualitative impact on the energy output and demand effects (with relatively small reductions in the economy-wide rebound estimates - the overall long-run economy-wide rebound drops from $38.35 \%$ to $33.97 \%$ - but with these impacted by stroner disinvestment and negative multiplier effects), this reduction in price responsiveness dampens the boost to activity from the positive supply shock of the increased efficiency in productive use of energy. In fact, there is evidence of a negative terms of trade effect due to the much more limited responsiveness of export demand to the general improvement in competitiveness. The domestic response is also more limited as reduced import elasticities mean a lower level of substitution away from imports towards now less expensive domestic production. The dampened boost to activity is, however, sufficient for negative substitution effects to dominate positive income effects in import use with a net reduction in reliance in imports (-0.09\% over the long-run) in this new central case scenario. However, the main result is that the economic expansion is dampened over the long-run $(0.08 \%$ compared to $0.18 \%$ in case 1a).

The remaining columns of Table 4 show the results of re-running the simulation using different elements of the econometric estimations reported in Tables 2 and 3 to parameterise the model. First, in the fifth and sixth columns we have the results case 2, where we run the model as in $1 \mathrm{~b}$ but with the country-level estimations reported in Table 2 for the KL-E nesting structure imposed in the production functions of all 21 sectors. That is, imposing the nesting structure in Figure $2 \mathrm{~B}$ (Case 2 nesting) and replacing the uniform 0.3 default elasticities with 0.13 at the upper KL-E nest and 0.04 at the lower K-L nest. What this does, while separating energy from the $\mathrm{K}$ and $\mathrm{L}$ inputs (which are constrained, at least in the short run), is reduce the substitution possibilities as energy becomes cheaper relative to other inputs. In turn, this dampens the positive competitiveness and income effects driving the economic expansion ( $0.05 \%$ over the long-run, compared to $0.08 \%$ in case $1 \mathrm{~b}$ ) and associated economy-wide rebound (which drops from $33.97 \%$ in $1 \mathrm{~b}$ to $12.44 \%$ in case 2 , the smallest long-run economy-wide rebound we find across all scenarios in Table 4), with increased pressures for negative multiplier and disinvestment effects as the price-driven demand responses are weakened.

In the final three cases in Table 4, we impose the LE-K nesting structure (Case 3, illustrated in Figure 2C). First, in case 3a, we impose the country level estimates from Table 2, with substitution elasticities of 0.31 and 0.18 replacing the default 0.30 at the upper LE-K and lower L-E nests respectively. In comparison to case 2 (the KL-E nesting), we this involves introducing higher elasticities which will allow stronger substitution effects. However, in case $3 \mathrm{a}$, energy now enters 
the production function at a nest where it first combines with a fixed factor of production (labour) which will put upward pressure on the composite LE price, which limits the strength of the substitution effect. Case $3 \mathrm{a}$ actually offers the most interesting comparison with the central case $1 \mathrm{~b}$. Given that the estimated elasticity at the LE-K nest (0.31) is effectively the same as the default (0.30), the differences in the results reported for cases 1a and 3a are explained by the more limited substitution possibilities resulting from the low value of 0.04 on the L-E nest, which knock on to more limited competitiveness effects (note the smaller long-run decrease in the CPI, $-0.22 \%$ in case $1 \mathrm{~b}$ and $-0.20 \%$ in $3 \mathrm{a})$ and income effects leading to a smaller long run increase in GDP $(0.06 \%$ compared to $0.08 \%$ in case 1a). Again, this increases pressure for stronger negative multiplier and disinvestment effects and we observe quite marked differences in the economy-wide rebound results (which fall from $54.41 \%$ and $33.97 \%$ for aggregate energy use in the short and long run respectively in case $1 \mathrm{~b}$ to $41.38 \%$ and $21.14 \%$ in $3 \mathrm{a}$ ) as a result of what is effectively a single variation in the parameterisation of the production function.

Next in case $3 b$, given the constraint imposed by combining energy with constrained labour in the lower L-E nest, we choose the LE-K configuration to consider the impacts of relaxing the labour supply constraint over time by allowing migration to fully adjust the labour market so that there is no long-run impact on real wage levels to negatively affect the growth in competitiveness. Case $3 \mathrm{~b}$ is run exactly the same as 3 a except for one variation (i.e. parameterisation is unchanged), which is to allow labour migration in response to changes in the UK real wage and unemployment rates relative to those prevailing externally. This change is reflected in the long-run result under $3 \mathrm{~b}$ where there is no change in the unemployment rate relative to the base (it falls by $-0.87 \%$ in case $3 a$ ). One key point to note is that this relaxation of the labour supply constraint is sufficient to offset the negative terms of trade effects that dampen the long-run economic expansion observed in $1 \mathrm{~b}, 2$ and $3 \mathrm{a}$ so that in case $3 \mathrm{~b}$ this is again bigger than in the short-run (with the GDP impact growing from $0.09 \%$ in the short-run to $0.11 \%$ in the long-run). However, note that economy-wide rebound is still dampened over the long-run due to the disinvestment effect.

Finally, in case $3 \mathrm{c}$, we return to the fixed labour supply configuration of $3 a$ but replace the countrylevel LE-K parameterisation in the case of the eight sectors highlighted in Table 3. Given that the sectoral level estimation reported in Table 3 generally produces higher elasticities of substitution for both nests in all eight cases, the results reflect stronger substitution effects driving positive stronger competitiveness and income effects and weaker negative multiplier and disinvestment effects. Case $3 c$ actually produces the largest economy-wide rebound effects of all the scenarios reported in Table 4. This is $41.7 \%$ over the long-run at the aggregate energy level, peaking at $66.96 \%$ for refined oil, 
compared to the next highest results observed in 1a, where the aggregate economy-wide rebound is $28.25 \%$ over the long-run and the peak is observed in gas at $47.68 \%$, with the dominance of rebound in refined oil in case $3 \mathrm{c}$ explained by the higher elasticities being introduced to sectors that are more intensive in their use of this energy type. However, note that the economic expansion is still more limited and impacted over time by negative terms of trade effects, relative to the first central case scenario (long-run GDP growth is $0.08 \%$, the same as in the central case 1b, compared to $0.18 \%$ in case $1 \mathrm{a}$ ). While the case $3 \mathrm{c}$ results further emphasise the importance of correctly identifying production substitution elasticities in considering rebound effects of increased energy efficiency (and highlight the need to consider these at the sectoral level), comparison with case 1a demonstrates that it is clearly also important to consider trade elasticities when considering economic expansion in an open economy such as the UK.

\section{Conclusions and directions for future research}

Despite the early working paper status of the research reported here, it is possible to identify some key conclusions and directs for future research. We list these as follows:

1. As we have found in our own previous work and that of others, a clear conclusion that can be drawn from the analyses presented here is that production elasticities are crucial in determining strength of range of general equilibrium effects driving economy wide rebound. Moreover, this is also clearly true in terms of the structure of production functions employed.

2. Nonetheless, we are most concerned about how much confidence we can have in the econometric estimations presented here. We have suggested different methods that could be adopted in the text above but invite comments and suggestions. However, more generally, there are issues in terms of interpretation and deciding between different econometric findings that are likely to remain of concern even if we improve our estimation methods.

3. We have focussed here on estimating production elasticities. However, our simulation results demonstrate that trade (import and export) elasticities also important and estimation of these should be focus of future work by researchers concerned with estimating economywide rebound. Similarly, assumptions regarding the supply conditions of primary inputs are important, here demonstrated in terms of labour supply expansion through migration. In the case of the UK, econometric consideration of labour migration to and from other EU nations is likely to be particularly importance.

4. Generally, as found in our previous work, supply conditions crucially important in determining the strength (and direction) of economy-wide rebound effects, particularly 
energy supply response to changing energy demand and prices. Thus, we emphasise the earlier conclusions of the Turner (2009) work that further exploration of negative rebound and disinvestment effects is required.

5. Moreover, while it has not been discussed here, a useful and important direction for future research will be to extend theoretical and empirical research will be to extend to consider (a) imperfectly competitive (particularly price setting) behaviour and regulated energy supply conditions; (b) impacts on and responsive of external energy suppliers.

6. Generally, consideration of economy-wide rebound effects in the literature has focussed on macro-level energy use in the country under study. However, given the global nature of the climate change problems we currently face, an important extension will be to consider spillover effects to energy demand in trade partners, both directly as activity levels change and in terms of energy embodied in trade flows (with the latter linking in particular to consideration of concepts such as carbon footprints).

\section{References}

Adkins, L.C., Rickman, D.S. and Hameed, A. (2003) Bayesian estimation of regional production for CGE modelling, Journal of Regional Science Vol. 43, pp.641-661.

Allan G, Hanley N, McGregor P, Swales K. and Turner K. (2007) The impact of increased efficiency in the industrial use of energy: a Computable General Equilibrium analysis for the United Kingdom, Energy Economics, Vol. 29, pp.779-798.

Barrell, R., Choy, A. and Kirby, S. (2006) Globalisation and UK trade, National Institute Economic Review, Vol. 195, pp. 63-67. DOI: 10.1177/0027950106064169.

Bergman, L. (2005) 'CGE modelling of environmental policy and resource management', Chapter 24 in Mäler and Vincent (eds), Handbook of Environmental Economics, Volume 3: Economywide and International Environmental Issues, Elsevier, North Holland.

Berndt,E.R and Wood, D. (1975) Technology, Prices, and the Derived Demand for Energy, The Review of Economics and Statistics, Vol. 57, pp.259-268.

Blanchflower, D.G. and Oswald, A.J. (1994) The Wage Curve, M.I.T. Press, Cambridge, Massachusetts.

Despotakis, K.A. and Fisher, A.C. (1988) Energy in a regional economy: a computable general equilibrium model for California, Journal of Environmental Economics and Management, Vol. 15, pp.313-330.

Dimitropoulos J. (2007) Energy productivity improvements and the rebound effect: an overview of the state of knowledge, Energy Policy, Vol.35, pp. 6354-6363 
Griffin, J and Gregory, P.R (1976) An Intercountry Translog Model of Energy Substitution Responses, The American Economic Review, Vol.66,5, pp. 845-857.

Harris, J.R. and Todaro, M. (1970) Migration, unemployment and development: a twosector analysis, American Economic Review, Vol. 60, pp.126-42.

Hertel, T.W. and Mount, T.D. (1985). The pricing of natural resources in a regional economy, Land Economics Vol. 61, pp.229-243.

Jorgenson, Dale W. (2007) 35 Sector KLEM (http://scholar.harvard.edu/jorgenson/data)

Jorgenson, Dale W. (2008) EU KLEMs dataset (http://scholar.harvard.edu/jorgenson/data)

Kemfert, C. (1998) Estimated substitution elasticities of a nested CES production function approach for Germany, Energy Economics, Vol. 20, pp. 249-264.

Lecca, P., Swales, J.K. and Turner, K. (2011) An investigation of issues relating to where energy should enter the production function, Economic Modelling, 28, pp. 2832-2841.

Li, P. and Rose, A. (1995) Global warming policy and the Pennsylvania economy: A computable general equilibrium analysis, Economic Systems Research, Vol.7, pp. 151-171.

Markandya, Anil and Suzette Pedroso-Galinato. 2007. How Substitutable is Natural Capital? Environmental and Resource Economics, Vol. 37, pp. 297-312.

Naqvi, F. (1998) A computable general equilibrium model of energy, economy and equity interactions in Pakistan, Energy Economics, Vol.20, pp. 347-373.

Partridge, M. and Rickman, D. (1998) Regional Computable General Equilibrium Modelling: A Survey and Critical Appraisal, International Regional Science Review, Vol. 21, 205-248.

Saunders, H.D. (2000a) A view from the macro side: rebound, backfire and KhazzoomBrookes, Energy Policy, 28, pp. 439-449.

Saunders, H.D. (2008) Fuel conserving (and using) production functions, Energy

Economics, Vol. 30, Issue 5, pp. 2184-2235.

Turner, K. (2009) Negative rebound and disinvestment effects in response to an improvement in energy efficiency in the UK Economy, Energy Economics, Vol. 31, pp. 648-666.

UK Energy Research Centre (2007) The rebound effect: an assessment of the evidence for economy-wide energy savings from improved energy efficiency, Report edited by S. Sorrell and produced by the UK Energy Research Centre. Dowload report at: http://www.ukerc.ac.uk/Downloads/PDF/07/0710ReboundEffect.

Van der Werf, E. (2008) Production functions for climate policy modeling: An empirical analysis, Energy Economics, Vol.30, pp. 2964-2979. 


\section{Appendix 1. US Results, 1961-2005}

\begin{tabular}{|c|c|c|c|c|c|c|}
\hline Sector (US) & Sigma KL,E & Sigma KL & Sigma KE,L & Sigma KE & Sigma EL,K & Sigma LE \\
\hline Agriculture & $0.19 *$ & $0.16 * * *$ & 0.12 & $0.13 * * *$ & 0.11 & $0.14 * * *$ \\
\hline Metal Mining & -0.19 & 0.01 & 0.13 & $0.21 * * *$ & $0.35^{*}$ & $0.40 * * *$ \\
\hline Coal Mining & 0.18 & $0.22 * * *$ & 0.01 & -0.01 & 0.19 & $0.19 * * *$ \\
\hline Oil and Gas Extraction & $1.55 * *$ & $1.37 * * *$ & 0.04 & 0.06 & $0.28 * *$ & $0.28 * * *$ \\
\hline Non-Metallic Mining & $0.36 * * *$ & $0.36 * * *$ & $0.31 * *$ & $0.32 * * *$ & 0.26 & $0.26 * * *$ \\
\hline Construction & $0.37 * * *$ & $0.36 * * *$ & 0.12 & $0.18 * * *$ & $0.32 * *$ & $0.31 * * *$ \\
\hline Food & 0.14 & $0.08 * * *$ & -0.13 & -0.04 & -0.05 & -0.02 \\
\hline Tobacco & 0.1 & $0.14 * * *$ & 0.06 & $0.11 * * *$ & $0.19 *$ & $0.22 * * *$ \\
\hline Textile Mill Products & 0.1 & $0.05 * * *$ & -0.01 & 0.03 & 0.24 & $0.16^{* * *}$ \\
\hline Apparel & 0.11 & $0.09 * * *$ & 0.05 & $0.09 * * *$ & $0.50 * * *$ & $0.40 * * *$ \\
\hline Lumber and Wood & $0.29 * *$ & $0.23 * * *$ & -0.03 & 0.03 & $0.70 * *$ & $0.65 * * *$ \\
\hline Furniture and Fixtures & $0.27 * * *$ & $0.24 * * *$ & $0.13^{*}$ & $0.15 * * *$ & $0.39 * *$ & $0.34 * * *$ \\
\hline Paper & $0.31 * * *$ & $0.25 * * *$ & 0.05 & $0.08 * * *$ & $0.60 * *$ & $0.54 * * *$ \\
\hline Printing and Publishing & $0.35 * * *$ & $0.33 * * *$ & 0.22 & $0.23 * * *$ & $0.26^{* *}$ & $0.25 * * *$ \\
\hline Chemicals & 0.19 & $0.16 * * *$ & 0.02 & $0.06 * * *$ & $0.32 *$ & $0.27 * * *$ \\
\hline Petroleum and Coal Products & $-0.36^{*}$ & $-0.12 * * *$ & $-0.23 * *$ & -0.04 & $0.19 * * *$ & $0.19 * * *$ \\
\hline Rubber and Plastics & 0.13 & $0.09 * * *$ & -0.04 & 0 & 0.17 & $0.14 * * *$ \\
\hline Leather & $0.40 * * *$ & $0.35 * * *$ & 0.04 & $0.12 * * *$ & $0.54 * * *$ & $0.51 * * *$ \\
\hline Stone, Clay, Glass & $0.33 * * *$ & $0.28 * * *$ & -0.13 & -0.04 & 0.15 & $0.13 * * *$ \\
\hline Primary Metal & 0.09 & $0.13 * * *$ & 0.15 & $0.17 * * *$ & $0.34 * * *$ & $0.33 * * *$ \\
\hline Fabricated Metal & 0.13 & $0.09 * * *$ & -0.14 & $-0.07 * * *$ & 0.21 & $0.17 * * *$ \\
\hline Non-Electical Machinery & $0.05 *$ & $0.06^{* * *}$ & 0.02 & $0.11 * * *$ & $0.26 * *$ & $0.17 * * *$ \\
\hline Electrical Machinery & $0.06 * *$ & 0.03 & 0 & $0.10^{* * *}$ & 0.05 & $0.05 * * *$ \\
\hline Motor Vehicles & $0.31 * * *$ & $0.35 * * *$ & 0.1 & $0.15^{* * *}$ & $0.54 * *$ & $0.51 * * *$ \\
\hline Transportation Equipment \& Ordnance & $0.26 * *$ & $0.36 * * *$ & 0.41 & $0.41 * * *$ & $1.12 * * *$ & $1.15^{* * *}$ \\
\hline Instruments & $0.27 * * *$ & $0.20 * * *$ & 0.02 & $0.10 * * *$ & $0.16 * *$ & $0.13 * * *$ \\
\hline Misc. Manufacturing & $0.30 * * *$ & $0.27 * * *$ & 0.05 & $0.10 * * *$ & $0.58 * * *$ & $0.53 * * *$ \\
\hline Transportation & $0.29 * * *$ & $0.22 * * *$ & -0.18 & $-0.07 *$ & $0.31 *$ & $0.23 * * *$ \\
\hline Communications & $0.25 * * *$ & $0.16^{* * *}$ & -0.06 & 0.01 & $0.23^{*}$ & $0.12 * * *$ \\
\hline Electric Utilities & 0.13 & $0.11 * * *$ & 0.08 & $0.05 * * *$ & -0.03 & -0.03 \\
\hline Gas Utilities & $0.53 * *$ & $0.55 * * *$ & -0.23 & -0.02 & $0.14 *$ & $0.11 * * *$ \\
\hline Trade & $0.27 * *$ & $0.23 * * *$ & $-0.08 *$ & 0.01 & 0.07 & $0.04 * * *$ \\
\hline Finance, Insurance and Real Estate & 0.21 & $0.17 * * *$ & -0.03 & -0.03 & 0.25 & $0.22 * * *$ \\
\hline Services & $0.48 * * *$ & $0.49 * * *$ & -0.03 & 0.03 & 0.1 & $0.07 * * *$ \\
\hline Government Enterprises & $0.38 * *$ & $0.31 * * *$ & -0.27 & -0.05 & $0.99 * * *$ & $0.99 * * *$ \\
\hline
\end{tabular}

$*, * *, * * *$ indicates $10 \%, 5 \%$, and $1 \%$ significance, respectively, against a null of sigma $=0$ 